\title{
A 333-YEAR RECORD OF THE MEAN MINIMUM TEMPERATURE RECONSTRUCTION IN THE WESTERN TIANSHAN MOUNTAINS, CHINA
}

\author{
LIANG JIAO ${ }^{1,2,3}$, SHENGJIE WANG ${ }^{1}$, YUAN JIANG ${ }^{2,3}$, XUERUI LIU ${ }^{1}$ \\ ${ }^{I}$ College of Geography and Environment Science, Northwest Normal University, No.967, Anning East Road, Lanzhou 730070, China \\ ${ }^{2}$ State Key Laboratory of Earth Surface Processes and Resource Ecology, Beijing Normal University, \\ No.19, Xinjiekouwai Street, Haidian District, Beijing 100875, China \\ ${ }^{3}$ Faculty of Geographical Science, Beijing Normal University, No. 19, Xinjiekouwai Street, Haidian District, Beijing 100875, China
}

Received 18 November 2018

Accepted 11 March 2019

\begin{abstract}
In this paper, a fragile ecological area in the Western Tianshan National Nature Reserve of China was selected as the research region, and Picea schrenkiana, which is sensitive to climate change, was selected as the research object. The mean minimum temperature in the growing season of the previous year (May to September) was the main limiting factor for tree radial growth based on an analysis of the relationship between chronological series and climatic factors during 1959-2012 $(r=-0.792, p<0.05)$. Moreover, the relationship was stable, which showed that tree rings can be used as alternative materials for climate reconstruction. Therefore, the mean minimum temperature of the previous year in 1680-2012 was reconstructed, and the explained variance of the reconstruction equation was $62.7 \%\left(R_{a d j}^{2}=62.0 \%, \mathrm{~F}=85.8\right)$. The 31 dramatically altered years were found via characteristic year analyses, and extreme changes occurred most often under relatively warm conditions. The mean minimum temperature in the reconstruction shows a clear warming trend by the 11-year moving average of the reconstructive series since the $1950 \mathrm{~s}$ (the temperature increase: $0.341^{\circ} \mathrm{C} /$ decade). The driving factors of the mean minimum temperature were influenced mainly by the interaction of solar activity and large-scale atmospheric-oceanic variability, especially the westerly circulations.
\end{abstract}

Keywords: dendroclimatology, mean minimum temperature reconstruction, response stability; Picea schrenkiana; Western Tianshan Mountains.

\section{INTRODUCTION}

Global warming has become an indisputable phenomenon (Marcott et al., 2013). During 1901-2012, the mean global temperature rose by $0.89^{\circ} \mathrm{C}$, and the trend of global warming has since strengthened. The average annual surface temperature increase is the strongest in the middle and high latitudes of the Northern Hemisphere; the warmest 30 years of the past $800-1400$ years were proba-

Corresponding author: L. Jiao

e-mail: jiaoliang@nwnu.edu.cn bly 1983-2012 (IPCC, 2013). This warming trend also has great uncertainty at the regional climate scale, showing a transition of "warm-dry" to "warm-wet" with a double increase in mean temperature and annual total precipitation since the end of the 1980s in Xinjiang, China (Shi et al., 2007). To better predict climate development in the future, it is necessary to understand the changing rules and driving mechanisms of historical climate. However, the limited instrumental data are not enough to study the evolution of the paleoclimate. Tree rings have the characteristics of high resolution, good continuity, wide sample distribution and accurate dating and have been applied in historical climate reconstruc- 
tions and in studies on the evolution of the paleoenvironment (Cook et al., 2010; Shao et al., 2010; Büntgen et al., 2011; Pederson et al., 2014).

Climate reconstruction based on tree rings is an important method of studying climatology. A large number of studies have been carried out worldwide, mainly in areas of wide distributions of coniferous trees in North America, northern Asia and Western Europe (Briffa et al., 1992; Popa and Kern, 2009; Matskovsky et al., 2017). Much of the climate history has been reconstructed in China, mainly in the northeastern and northwestern regions and on the Tibetan Plateau (Zhang et al., 2011; Zhu et al., 2011; Peng et al., 2013; Yu et al., 2018). The Tianshan Mountains, which are located in the arid and semi-arid inland area of Northwest China, represent an ideal area for the study of dendroclimatology due to its great climatic fluctuations and the highly sensitive coniferous trees (Cheng et al., 2012). A large number of climate reconstructions have been carried out in the Tianshan area since the 1960s and 1970s. Streamflow reconstructions have focused mainly on the central and western regions of the Tianshan Mountains, such as the Manas River, Jinghe River, Urumqi River and Guxiang River (Yuan et al., 2007; Chen and Yuan, 2016; Yang et al., 2016; Zhang et al., 2016). Precipitation reconstructions have been distributed throughout the Tianshan Mountains, especially in the western Tianshan Mountains (Yuan et al., 2001; Shang et al., 2010; Zhang et al., 2013a; Liu et al., 2015; Zhang et al., 2015; Chen et al., 2017). Drought reconstructions have been concentrated in the central and eastern Tianshan Mountains based on the Palmer drought severity index (PDSI), but fewer drought reconstructions have been based on the better Standardized Precipitation Evapotranspiration Index (SPEI) (containing precipitation, temperature, relative humidity, solar radiation, water vapour pressure, and wind speed) (Chen et al., 2013, 2016; Xu et al., 2015a; Xu et al., 2015b; Jiang et al., 2017). Temperature reconstructions have also been studied throughout the Tianshan Mountains, but they have mainly focused on the reconstruction of the mean temperature and the mean maximum temperature; research on the mean minimum temperature is scarce (Chen et al., 2009, 2012a; Chen et al., 2009; Shang et al., 2011; Yu et al., 2013; Zhang et al., 2013b).

Climate reconstruction is based on the "uniformitarian principle', with a stable relationship between tree radial growth and climatic limiting factors (Fritts, 1976). However, some studies have discovered a 'divergence problem', with decreasing sensitivity of radial growth to the temperature response in both the middle-high latitudes and the high-altitude regions of the Northern Hemisphere as a result of the strengthening trend of global warming, which has put forward a great challenge to the reconstruction of the historical climate based on tree rings (Briffa $e t$ al., 1998; D'Arrigo et al., 2008; Franceschini et al., 2012). Moreover, the results of divergent responses are relatively complex, such as those involving Larix olgensis in the Changbai Mountains in Northeast China, Sabina przewalskii in the northeastern part of the Tibetan Plateau, Sabina przewalskii in the eastern part of the Qilian Mountains and Pinus tabulaeformis in the Helan Mountains in Northwest China, all of which have diverged (Zhang et al., 2009; Shen et al., 2016; Wang et al., 2016). However, Picea crassifolia in the northeastern part of the Tibetan Plateau has a relatively stable response to climate (Zhang and Wilmking, 2010). Studies on divergent responses in the Tianshan Mountains are relatively scarce, but Larix sibirica has an unstable response to climate change in the eastern Tianshan Mountains (Jiao et al., 2015). Therefore, whether Schrenk spruce also results from a divergent response in the western Tianshan Mountains remains to be further tested. Because of the increasing trends in both the mean temperature and total precipitation in the western Tianshan Mountains, historical climate reconstruction based on testing the temporal dynamic stability of the growth-climate relationship would be more accurate. Moreover, climate reconstruction also requires revealing the driving mechanism on a large space-time scale, which is conducive to predicting climate trends in the future. Therefore, the main aims of this paper are as follows: (1) to both determine the main controlling climate factors limiting the radial growth of Schrenk spruce stability of relationship; (2) to reconstruct the mean minimum temperature of the growing season from 1680-2012, and clear rule of climatic change; and (3) to reveal the main driving factors of climate change in the western Tianshan Mountains.

\section{MATERIAL AND METHODS}

\section{Study site and sample core acquisition}

Samples were collected from the western region of the Tianshan Nature Reserve of Kurdistin in the Tianshan Mountains, Xinjiang, China (Fig. 1). The region has a temperate continental semi-arid climate. The annual average precipitation is $508.3 \mathrm{~mm}$, which is relatively concentrated in the summer (Fig. 2a). The annual mean temperature is $3.4^{\circ} \mathrm{C}$, with a mean temperature of $-11.2^{\circ} \mathrm{C}$ in the coldest month (January) and a mean temperature of $15.1^{\circ} \mathrm{C}$ in the hottest month (July). Schrenk spruce (Picea schrenkiana), which grow naturally at 1500-2800 m above sea level, is one of the dominant tree species in the Tianshan Mountains. The sampling site was labelled as KRD (43 ${ }^{\circ} 8.914^{\prime} \mathrm{N}, 82^{\circ} 52.837^{\prime} \mathrm{E}, 1650-1670 \mathrm{~m}$ a.s.l.). To minimize non-climatic effects on tree growth, only trees with no injury and disease in open stands were sampled. In general, two cores were taken from each tree with the borers following the standard methods of treering sampling (Fritts, 1976). A total of 50 cores from 25 living Schrenk spruce trees were selected using $5-\mathrm{mm}$ increment borers in June 2013. 


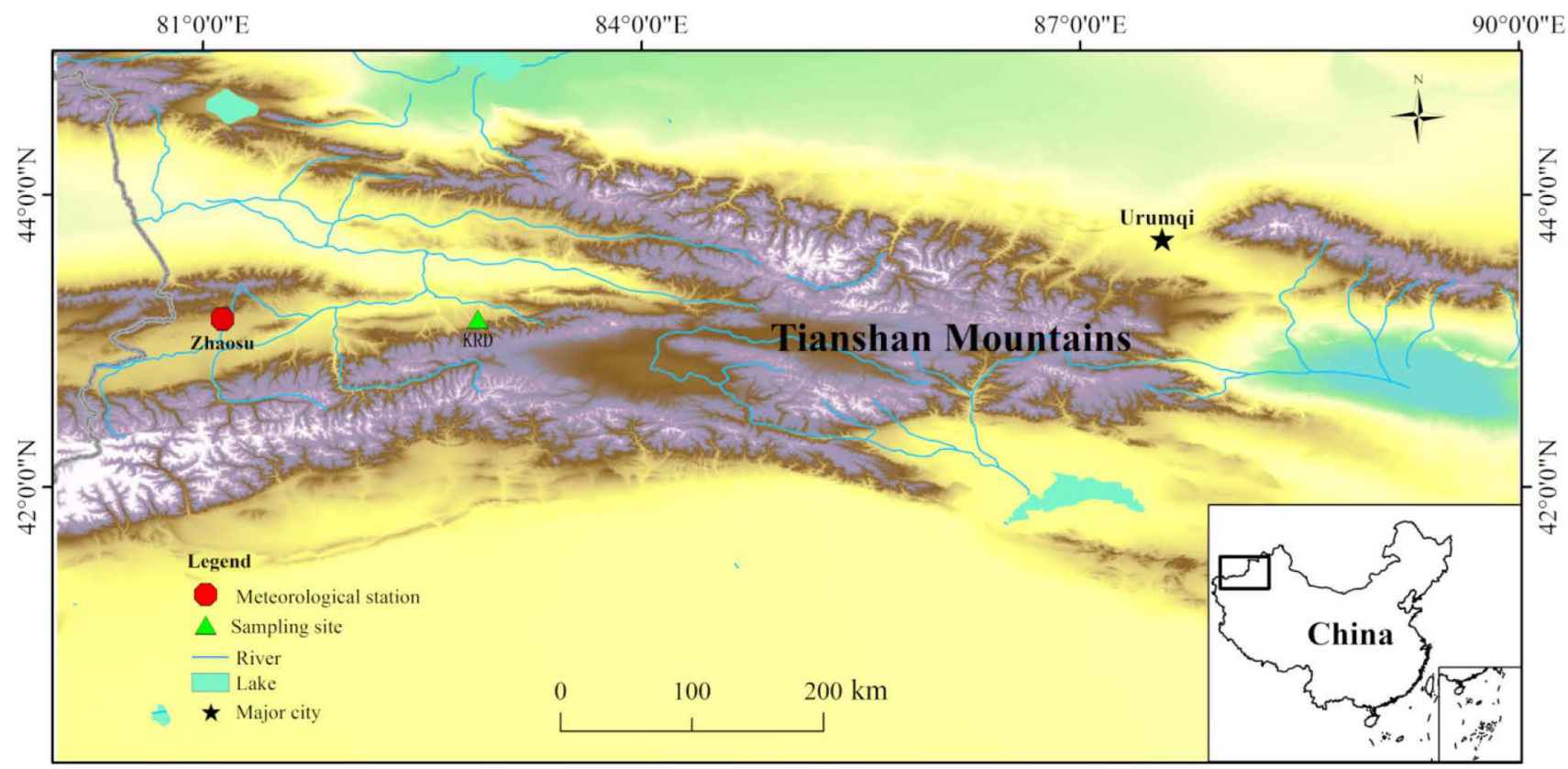

Fig. 1. Locations of the sampling site and the nearest meteorological station (Tianshan Mountains).
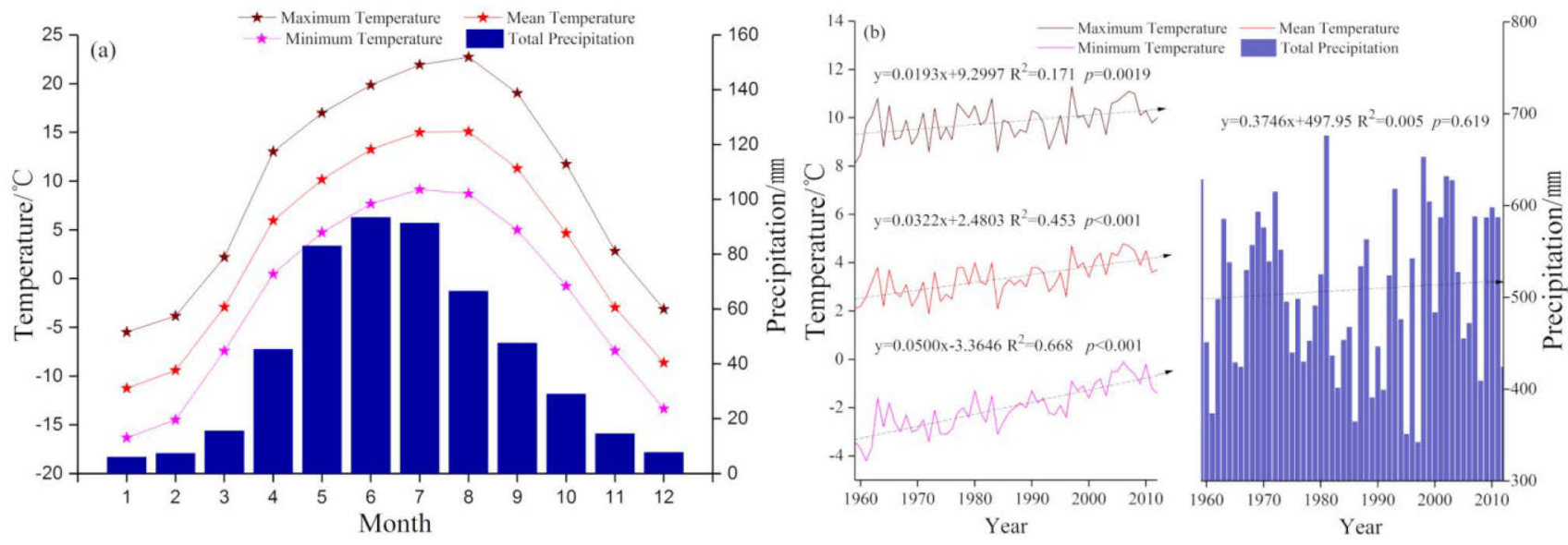

Fig. 2. Temperature and total precipitation during 1959-2012 using records from the Zhaosu meteorological station, Northwest China. (a) Monthly total precipitation and mean, minimum and maximum temperatures averaged; (b) Variation trends of annual total precipitation and mean, minimum and maximum temperatures; the lines with arrows represent the simulated trends by linear regression.

\section{Chronology development}

In the laboratory, the tree cores were mounted on woody supports, air dried and sanded to produce clearly visible boundaries for identification, and three cores with ambiguous rings and large growth-curve variations were removed. The rings of the remaining 47 cores were measured with $0.001-\mathrm{mm}$ resolution using the LINTAB measurement system (TM5, Rinntech, Heidelberg, Germany) (Schweingruber, 1996; Stokes and Smiley, 1968). The quality of all measurement series was verified using the COFFECHA program (Holmes, 1983). The measured ring widths were detrended with negative exponential curves or straight lines (Melvin and Briffa, 2008; Cook et al., 2013). A cubic spline with a 50\% frequency-response cut-off equal to $67 \%$ of the series length was also used in several cases when both types of previous curves failed. All the detrended series were then combined into a composite chronology using a robust (biweight) mean function (Cook and Kairiukstis, 1990). After all these processes, three kinds of chronologies of the KRD sampling site were obtained: standard chronology (STD), residual chronology (RES), and arstan chronology (ARS). The ultimate reliable standard chronology (STD) began in $1680 \mathrm{AD}$, which was determined based on a subsample signal strength (SSS) value that exceeded 0.85 (Wigley et al., 1984) (Fig. 3). 


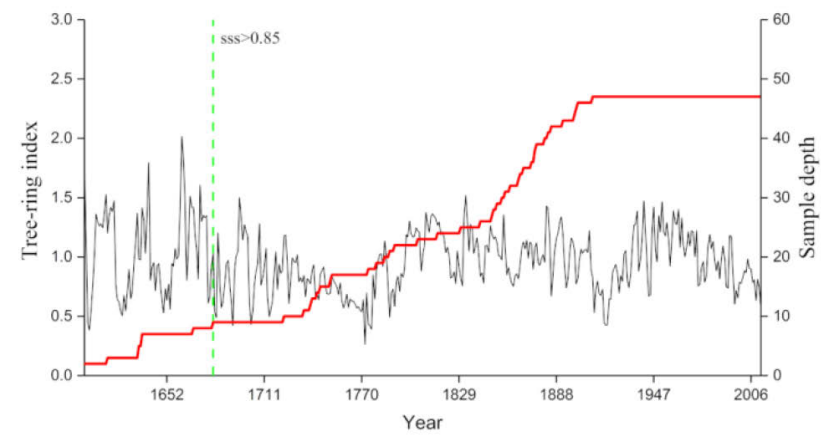

Fig. 3. The tree-ring standard chronology for KRD (black line) and the sample depth (number of tree cores) over time (red line). The vertical dashed line indicates the beginning of the reliable chronology with a threshold of SSS $>0.85$.

\section{Meteorological data}

The temperature and precipitation data were obtained from Zhaosu (ZS) meteorological stations $\left(43.15^{\circ} \mathrm{N}\right.$, $83.13^{\circ} \mathrm{E}, 1854 \mathrm{~m}$ a.s.l.) of the National Meteorological Information Center (NMIC) of China near our sampling site $(149.3 \mathrm{~km})$ (Fig. 1). The climatic data include monthly maximum, mean and minimum temperatures, total precipitation and SPEI from 1959 to 2012. The SPEI were calculated using R (R Core Team, 2014) with the R package 'SPEI' (Beguería and Vicente-Serrano, 2013). The climate data show a significant increasing trend of the annual mean maximum temperature (rising rate: $0.193^{\circ} \mathrm{C} /$ decade, $p=0.0019$ ), mean temperature (rising rate: $0.322^{\circ} \mathrm{C} /$ decade, $\left.p<0.001\right)$ and mean minimum temperature (rising rate: $0.500^{\circ} \mathrm{C} /$ decade, $p<0.001$ ); however, the increasing trend of the annual precipitation did not reach a significant level (rising rate: 3.746 $\mathrm{mm} /$ decade, $p=0.619)$ (Fig. 2b).

\section{Statistical methods}

In this study, Pearson correlation coefficients were calculated to identify the relationships between tree-ring chronology and the major controlling climate factors. The temporal stability of the growth-climate relationship was tested by a moving correlation function with a 30-year time window using the Dendroclim2002 program (Biondi and Waikul, 2004). A linear regression model was used as a transfer function to derive the reconstruction, and the statistical fidelity of the regression model was validated with split-sample calibration-verification tests (Cook and Kairiukstis, 1990). The statistics calculated for testing the accuracy of the reconstruction include the explained variance $\left(R^{2}\right)$, adjusted explained variance $\left(R_{a d j}^{2}\right)$, F value, sign test (ST), reduction of error (RE) and coefficient of efficiency (CE). RE and CE values greater than zero indicate a good reconstruction model fit. The multi-taper method (MTM) of spectral analysis was applied to examine the characteristics of local climate variability in the frequency domain over the full range of our reconstruction (Mann and Lees, 1996). Our analysis used $5 \times 3 \pi$ tapers and a red noise background. Furthermore, to test whether our reconstruction contains a regional climate signal, we used KNMI Climate Explorer (http://climexp.knmi.nl) to generate correlation fields with synoptic-scale climate parameters, such as the gridded data sets of the Climate Research Unit (CRU) TS 3.24 (Jones and Harris, 2008).

\section{RESULTS}

\section{Relationship between radial growth and climate}

To determine the radial growth and dominant climate factors of trees, we analyzed the relationship between tree-ring width chronology and climate factors via Pearson correlation analysis (Fig. 4). Tree-ring width chronology was significantly positively correlated with total precipitation and SPEI in July (precipitation: $r=0.320$, $p<0.05$; SPEI: $r=0.349, p<0.01$ ), September (precipitation: $r=0.291, p<0.05$; SPEI: $r=0.278, p<0.05$ ) and May to September of the previous growing season (precipitation: $r=0.276, p<0.05$; SPEI: $r=0.291, p<0.05$ ). The tree-ring width chronology was significantly negatively correlated with the mean temperature in May, June, July, August, September, October, and the growing season, which exhibited the strongest correlation with the mean minimum temperature in the growing season of the previous year $(r=-0.792, p<0.01)$. Moreover, the firstorder-difference correlation coefficient between tree-ring width chronology and the mean minimum temperature was $-0.437(p<0.01)$, which shows that the mean minimum temperature was the most important controlling factor for the radial growth of trees in the study region.

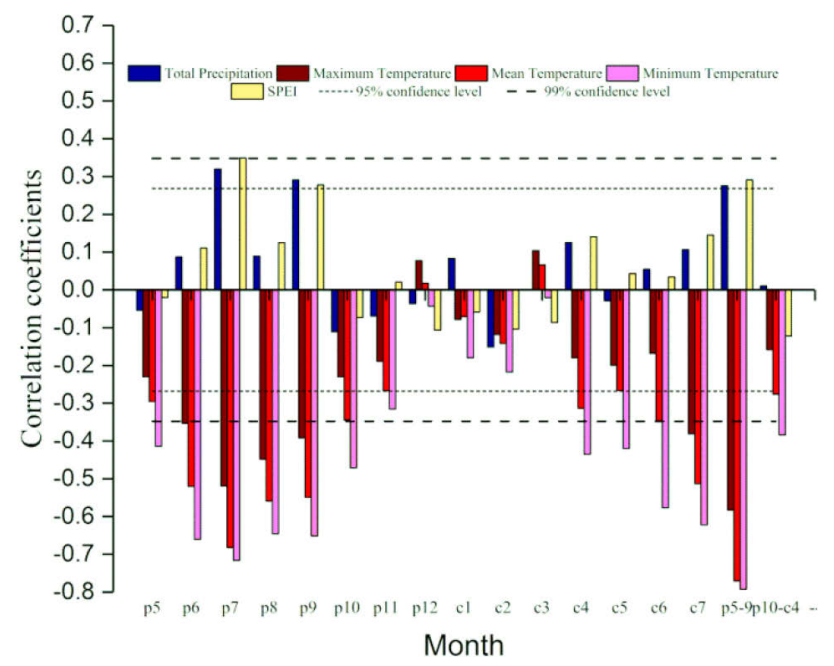

Fig. 4. Correlations between tree-ring width chronologies of Schrenk spruce and monthly climate factors (total precipitation as well as mean, minimum and maximum temperatures) during 1960-2012 (the dotted lines represent significance at the 0.05 level, and the straight lines represent significance at the 0.01 level. p: previous year, c: current year, Number: month). 
The response stability of the radial growth to the mean minimum temperature was tested via a moving correlation (1959-2012) (Fig. 5). The average value of the moving correlation is $-0.403(p<0.05)$, and the temporal dynamics of the response to limiting climate factors were stable $(p=0.5956)$, which indicated that there is no 'divergence problem' and that climate reconstruction could be carried out based on the tree-ring width chronologies of Schrenk spruce.

\section{Transfer function and verification}

Based on the results of the correlation analysis and moving correlation, we reconstructed the mean minimum temperature in the growing season of the previous year using the standard chronology. A linear regression model was used to describe the relationship between the treering chronology (STD) and mean minimum temperature. The model was designed as follows:

$\mathrm{T}_{\text {min5-9 }}=-3.5821 \times \mathrm{STD}+10.449$

Where $\mathrm{T}_{\text {min5-9 }}$ represents the mean minimum temperature value from May to September at a time scale of 5 months and STD represents the tree-ring index for the next year.

The model explained that the variance of the reconstruction was $62.7 \%$ (62\% after adjusting for the degrees of freedom) for the calibration period (1959-2012), and

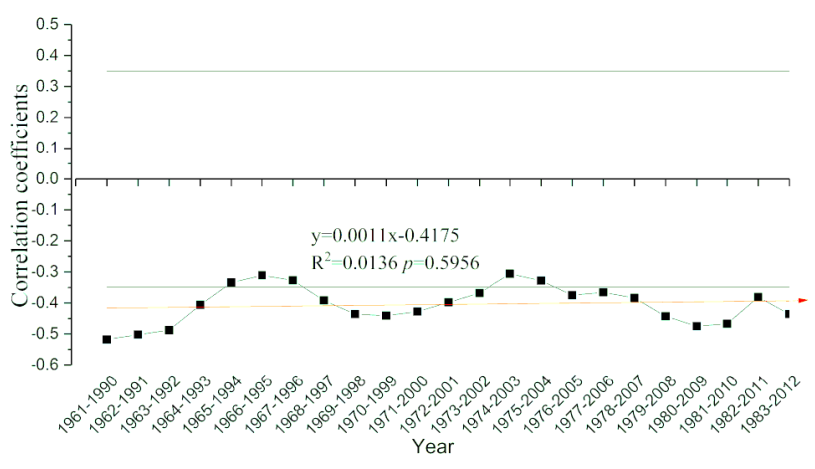

Fig. 5. Moving correlation results between the tree-ring width chronology and mean minimum temperature. Moving window: 30 years. The grey line represents significance at the 0.05 level. Variation trends of correlation coefficients; the red line with arrow represent the simulated trends by linear regression (1961-2012). the reconstruction series of the mean minimum temperature and observations were significantly correlated $(r=0.792, p<0.01)$. Moreover, the first differences in the reconstruction and observations were also significantly correlated $(r=0.43, p<0.01)$, and the value of the F-test was $85.8(p<0.01)$. The results showed a good match between the reconstructed values and the observed values (Fig. 6). The reliability and stability of the model were further validated by split-sample calibrationverification tests, showing that the remaining $r, \mathrm{~F}$, and ST tests had reached significance at a $99 \%$ confidence level during 1986-2012 (Table 1). The particularly rigorous indicator of the model skill of the RE and CE were both positive, suggesting that the linear regression model was statistically validated and could be used for climate reconstruction.

\section{$T_{\text {min5-9 }}$ reconstruction from 1680 to 2012 AD}

Based on the response analysis and regression model, the $T_{\min 5-9}$ series of the KRD region during 1680-2012 was rebuilt, which can reflect the interannual variation in the mean minimum temperature (Fig. 7a). Three cooler periods (1680-1707, 1802-1911, 1935-1997) and three warmer periods (1708-1801, 1912-1934, 1998-2012) were found in the past 333 years by the 11-year moving average of $\mathrm{T}_{\min 5-9}$, and there was a clear warming trend (temperature increase: $3.7^{\circ} \mathrm{C}$ ) in the calibration period (Fig. 7a). The average value of $\mathrm{T}_{\min 5-9}$ was $7.00^{\circ} \mathrm{C}$, and the standard deviation $(\sigma)$ was $0.479^{\circ} \mathrm{C}$. Thirty-one years

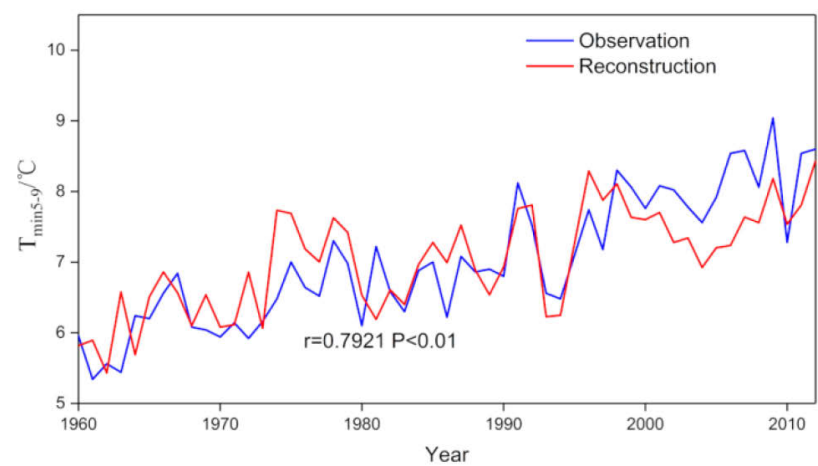

Fig. 6. Comparison of reconstructed (red line) and observed (blue line) $T_{\text {min5-9 }}$ data from May to September during 1959-2012 AD.

Table 1. Calibration and verification statistics for the $T_{\min 5-9}$ reconstruction in the western Tianshan Mountains.

\begin{tabular}{lccccc|ccccc}
\hline \multicolumn{9}{c}{ Calibration } & \multicolumn{4}{c}{ Verification } \\
\hline Period & $\boldsymbol{r}$ & $\boldsymbol{R}^{2}$ & $\boldsymbol{R}^{2}$ adj & $\boldsymbol{F}$ & $\boldsymbol{S T}$ & Period & $\boldsymbol{r}$ & $\boldsymbol{R} E$ & $\boldsymbol{C E}$ \\
\hline $1960-1985$ & $0.655^{* *}$ & 0.429 & 0.405 & $17.9^{* *}$ & $23+/ 3-^{* *}$ & $1986-2012$ & $0.710^{* *}$ & 0.534 & 0.485 \\
$1986-2012$ & $0.710^{* *}$ & 0.503 & 0.484 & $25.3^{* *}$ & $19+/ 8-$ & $1960-1985$ & $0.655^{* *}$ & 0.744 & 0.458 & $23+/ 8-$ \\
$1960-2012$ & $0.792^{* *}$ & 0.627 & 0.62 & $85.8^{* *}$ & $46+/ 7-^{* *}$ & & & & & \\
\hline
\end{tabular}

${ }^{*}$ Significant at the $95 \%$ confidence level, ${ }^{* *}$ Significant at the $99 \%$ confidence level

$R^{2}$ (the explained variance), $R^{2}$ adj (adjusted explained variance), $F$ value, ST (sign test), $R E$ (reduction of error) and CE (coefficient of efficiency). 


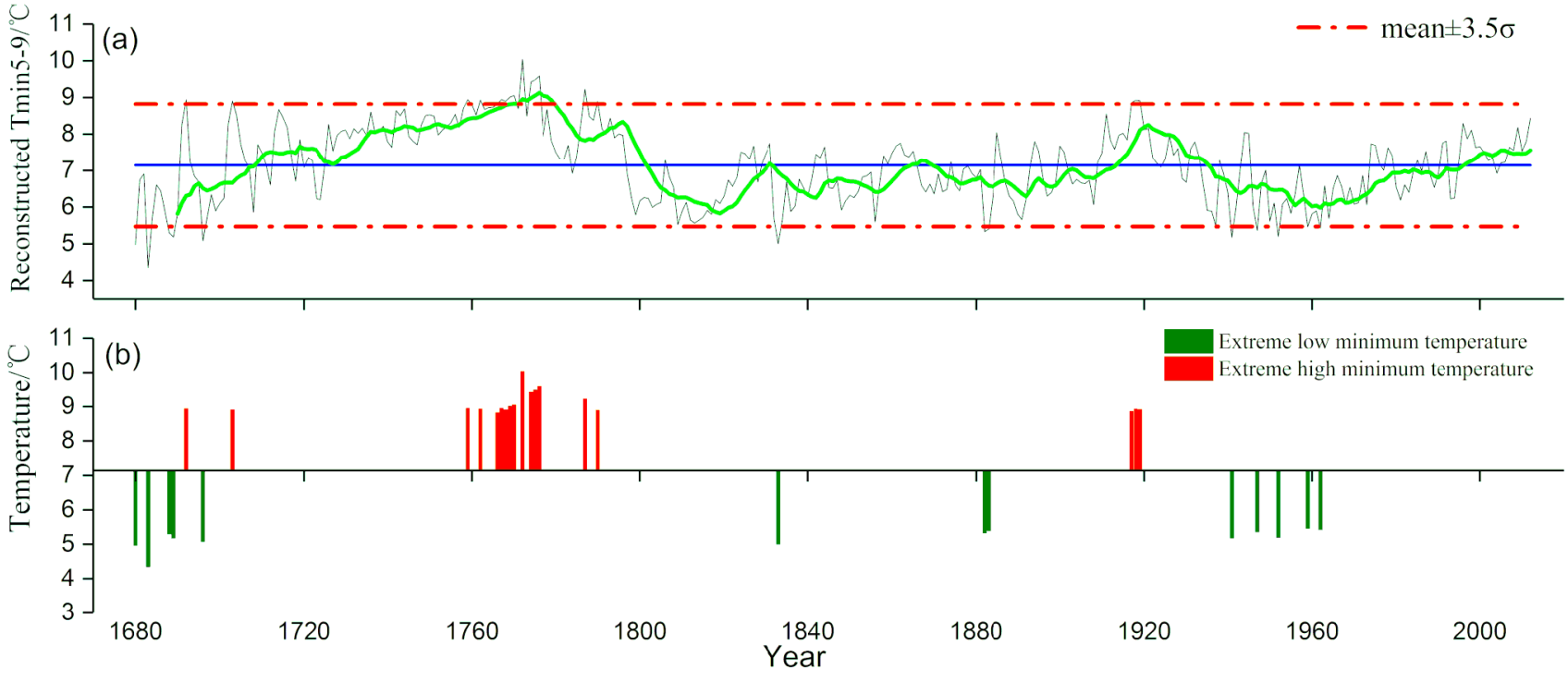

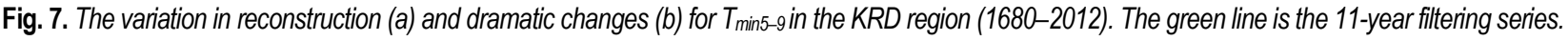

of intense change were determined based on the corresponding value $>$ mean $+3.5 \sigma(=8.68)$ or $<$ mean $-3.5 \sigma$ $(=5.33)$; the number of extreme years smaller than the average was 8 , and the number extreme years above the average was 9 , which accounted for $47 \%$ and $53 \%$ of the total extreme years, respectively (Fig. 7b). Moreover, we found that the frequency of the extreme years appeared to be greater under relatively warm conditions.

Some significant low-and high-frequency cycles of the reconstruction series of the mean minimum temperature were revealed by the MTM analysis in the growing season of the previous year (Fig. 8). Low-frequency peaks were found at 56-114 yrs (99\%), 17.9-yr (95\%), 11.3-yr (90\%), 10.9-yr (90\%) and 10.1-yr (95\%). Highfrequency peaks were found at 5.4-5.9 yrs (99\%), 4.2-yr (99\%), 3.9-yr (99\%) and 2.1-yr (99\%).

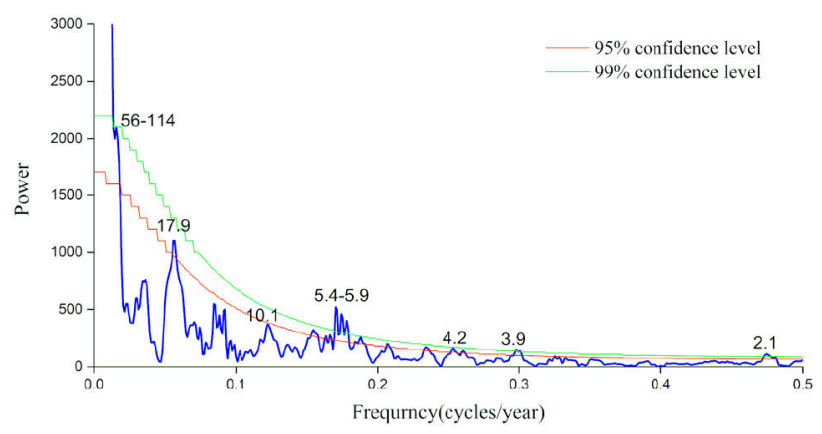

Fig.8. The periodicity results of $T_{\min 5-9}$ during 1680-2012. The red and green lines indicate the 95 and $99 \%$ confidence levels, respectively.

\section{DISCUSSION}

\section{Response of the radial growth of trees to climate}

Climate reconstruction based on tree-ring enables us to understand not only the changes in the past climate but also the distinct climatic change rules and mechanisms and allows speculation of the trend of future climate development. In this paper, the mean minimum temperature of the growing season of 333 years in the western Tianshan Mountains was rebuilt by the samples of Schrenk spruce tree rings collected in the Western Tianshan National Nature Reserve of Kurdistan, and its variation and driving factors were analyzed.

The growth of trees is concentrated mainly in the growing season, so climate change during spring and summer has a great influence on the radial growth of trees (Chen et al., 2009; Peng et al., 2005; Yu et al., 2013; Linderholm et al., 2015; Zhang et al., 2018). Our study also confirmed these results, showing that the radial growth of Schrenk spruce has a significant correlation with the temperature from May to September of the previous year; the strongest correlation was with the mean minimum temperature $(r=-0.792, p<0.01)$ (Fig. 4). The trend of increasing temperature was caused mainly by a significant increase in the mean minimum temperature in the study, suggesting a greater rising rate of the mean minimum temperature (mean maximum temperature rising rate: $0.193^{\circ} \mathrm{C} /$ decade; mean temperature rising rate: $0.322^{\circ} \mathrm{C} /$ decade). Therefore, the mean minimum temperature increase was also recorded in the radial growth of Schrenk spruce (Fig. 2b). On the one hand, many terrestrial biogeochemical processes of plants are regulated by the mean minimum temperature, such as plant respiration, plant productivity, plant nutrient uptake and so on (Pal- 
ombo et al., 2014). With the increase in mean minimum temperature, the nutrient consumption of tree respiration increases, which negatively affects radial growth and forms a narrow ring (Yu et al., 2013). Cellular growth in plants is believed to occur mainly in the evening, and the mean minimum temperature is the dominant factor that restricts cellular production rates and controls the length of the growing period by acting on tissue formation ( $\mathrm{Li}$ et al., 2013). On the other hand, the increase in temperature can also increase the evapotranspiration of soil water, and it is particularly easy to cause the shallow-rooted Schrenk spruce to be affected by water deficit. Meanwhile, we also found that the tree-ring width chronology was significantly correlated to the SPEI of May to September in the previous year $(r=0.291, p<0.05)$, which also proved the effect of drought on the radial growth of trees. For example, the growth rate of Schrenk spruce on a steep slope in the eastern and western Tianshan Mountains would decline rapidly in the face of long-term drought due to its shallow root system (Wu et al., 2013; Jiao et al., 2017). Moreover, the response of trees to climate factors has lagged effect, showing that the accumulation of photosynthetic nutrients in the previous year has a significant effect on tree growth in the current year. Pinus sylvestris in northern Inner Mongolia and Sabina przewalskii in both the northwestern Qilian Mountains and the northeastern region of the Qaidam basin are both limited by climatic factors of the previous year (Shao et al., 2005; Liu et al., 2009; Yang et al., 2011; Chen et al., 2012a). In our study regions, similar results were also found, in that the radial growth of trees was negatively correlated with the mean minimum temperature in the growing season of the previous year. The degree of narrow rings would increase as the temperature continues to rise in the future (Fig. 9).

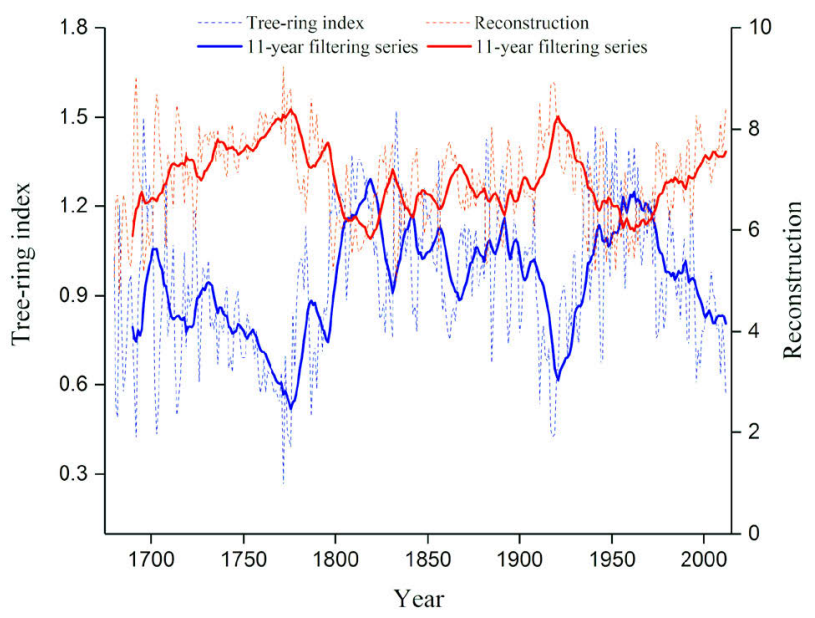

Fig. 9. The relationship between the tree-ring index (blue dotted line) and the main controlled climate factor (red dotted line). The thick line is the 11-year filtering series.
Tree rings are important substitute materials for paleoclimate reconstruction, which has been confirmed in a large number of studies on tree-ring climatology (White et al., 2014; Jiao et al., 2016; Ponocna et al., 2016; Jiang et al., 2017). However, divergent phenomena have taken place with global warming, and dynamic responses have a great impact on the accuracy of the results of climate reconstruction based on tree rings (D'Arrigo et al., 2008; White et al., 2014; Jiao et al., 2015; Shen et al., 2016). Therefore, it is necessary to test the stability between radial growth and the main limiting climatic factors before climate reconstruction. There was no divergent response, and the response of Schrenk spruce to the climate factors was stable based on examination of the dynamic growth-climate relationship. Reconstruction results by divergent tests were relatively more reliable during the past 500 years of precipitation reconstruction in the southern part of Germany based on Picea abies and Abies alba (Wilson and Elling, 2004).

\section{Reconstruction of the spatial representation and re- gional comparison of the mean minimum temperature series}

To understand the spatial representation of the reconstruction results, the correlation coefficients were calculated between the measured values and reconstruction values of the mean minimum temperature and the regional CRU lattice from 1959-2012 (Fig. 10). Both the measured values and reconstruction values were significantly positively correlated with most regions in central Asia. Therefore, the temperature signal in the study regions can be captured based on the mean minimum temperature of the reconstruction of Schrenk spruce, and it can represent the temperature change characteristics in larger regions.

To further verify the reliability of the results, the reconstruction series were compared with other reconstruction series near the study regions. Our reconstruction series significantly correlated with the mean minimum temperature series of Gongnaisi $(r=0.108, p<0.05$, 1680-2008) and Shawan $(r=0.162, p<0.01,1680$ 2001), and PDSI series $(r=-0.307, p<0.01,1680-2008)$ in Tianshan Mountains. Especially, there is consistency between our reconstruction series and both the mean minimum temperature of May to August in Gongnaisi during the summer and the mean minimum temperature of June to August in Shawan, Xinjiang, during 1708 1765, 1820-1854, 1945-1976, and 1998-2008 (Yu et al., $2012,2013)$. The warm and cold periods of our reconstruction series were also the same as the mean maximum temperatures of June to August in Yili, Xinjiang (the warm period during 1708-1732, 1756-1774, 1794-1801, and 1909-1932 and the cold period during 1682-1616, 1828-1844, 1870-1908, 1935-1943, and 1949-1972) (Fan et al., 2008). In comparison with the spring drought in the Tianshan Mountains, the wet and dry period coincided with the our cool and warm period of reconstruction during 1680-1692, 1842-1857, 1875-1908, 1933- 
(a)

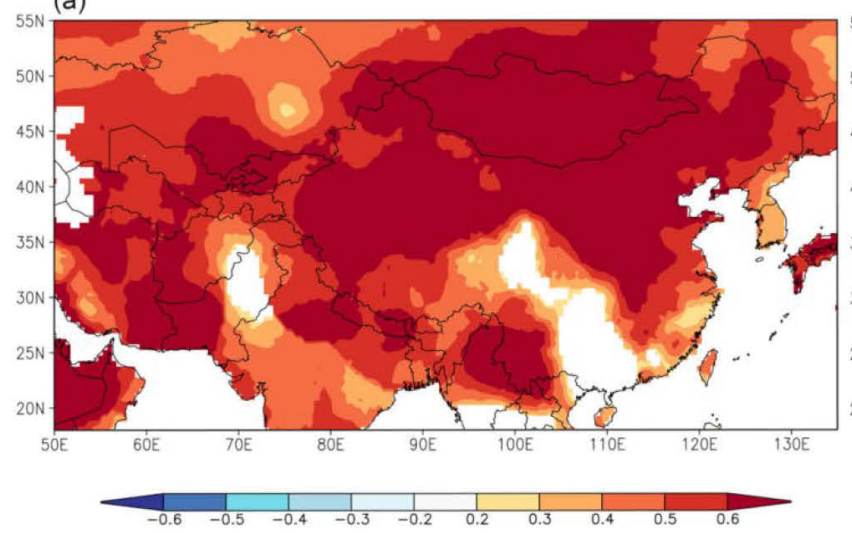

(b)

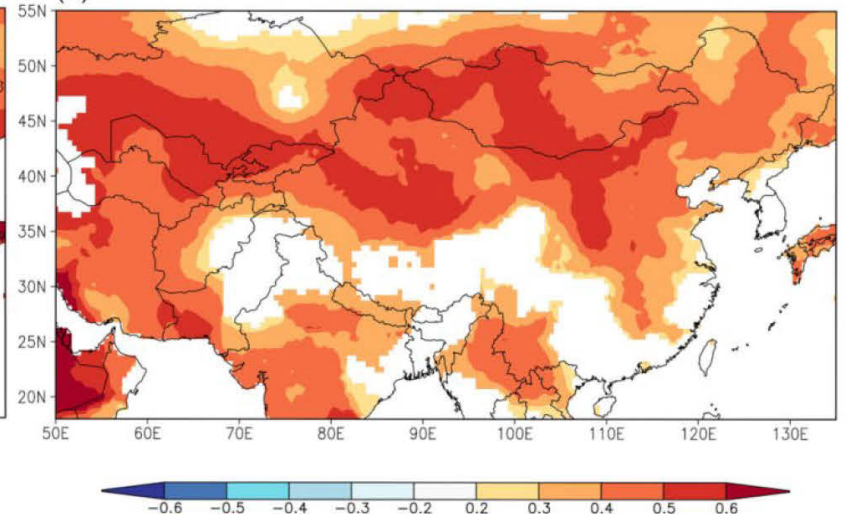

Fig. 10. Spatial correlation patterns between regional $T_{\min }$ data (CRU self-calibrating $T_{\min }$ of 3.21) and the data of observed $T_{\min }(a)$ and reconstructed

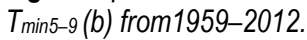

1938, 1957-1974 and 1708-1722, 1758-1790, 19081934 (Zhang et al., 2017). These results all indicated the accuracy of our reconstruction of the mean minimum temperature in the growing season from another aspect.

In addition, the reconstruction results were compared with the drought events recorded in the historical documents of Xinjiang regions and the volcanic eruption years by high/low mean percentage, it is the reconstructed value minus the reconstructed average divided by the reconstructed average. (Wen et al., 2006; Chen et al., 2012a). The mean minimum temperature reconstruction had a good correspondence with the drought events in the Xinjiang region, and the values of the drought events were significantly higher than the average reconstructed temperatures, especially in some extreme drought years, such as 1775, 1919, and 1945 (Chen et al., 2013; Liu et al., 2013; Zhang et al., 2017). Radial growth of trees is also responsive to volcanic eruptions and temperature changes had been importantly affected by many upper westerly circulation and low latitude tropics massive volcanic eruptions in central Asia (Chen et al., 2012b). After the eruption, the width of the growth-rings increased due to reduced temperature and intensified precipitation. Therefore, it was found that the temperature in the year of volcanic eruptions was obviously lower than the average value of the reconstructed temperature (Table 2).

\section{Relationship between reconstruction results and ex- ternal environmental factors}

Regional climate change is affected by large-scale climate-forcing factors, such as solar activity and atmospheric-oceanic variability (Fang et al., 2010; Linderholm et al., 2015; Rydval et al., 2017).

On the one hand, based on the MTM analysis results, the temperature changes in the study area are mainly influenced by the solar activity via the mean minimum temperature within approximately 11-year periods ( $\mathrm{Li}$ et al., 2006; Wang et al., 2015). The cycle similarity of the
Table 2. The dry and volcanic years recorded in historical documents (high/low mean percentage were calculated with the reconstructed value minus the reconstructed average divided by the reconstructed average).

\begin{tabular}{|c|c|c|}
\hline & $\begin{array}{l}\text { Year (high/low } \\
\text { mean percentage) }\end{array}$ & Historical Document Records \\
\hline 1 & $1775(23.98 \%)$ & $\begin{array}{l}\text { Drought in Xinjiang in } 1775 \text { was of such } \\
\text { devastating proportions that } 80 \% \text { of the grain } \\
\text { crops failed. }\end{array}$ \\
\hline 2 & $1874(3.33 \%)$ & $\begin{array}{l}\text { Tacheng, Qitai and Jimusal counties drought, } \\
\text { harvest apology. Changji drought and locust } \\
\text { frequency. }\end{array}$ \\
\hline 3 & $1893(11.36 \%)$ & $\begin{array}{l}\text { Drought occurred in Dihua (Urumqi now) and } \\
\text { Changji regions in } 1893 .\end{array}$ \\
\hline 4 & $1913(8.39 \%)$ & Droughts in the town of Zhenxi county. \\
\hline 5 & $1917(26.55 \%)$ & $\begin{array}{l}\text { Yili, Yingjisha, Pishan and other counties } \\
\text { drought. }\end{array}$ \\
\hline 6 & $1918(27.42 \%)$ & $\begin{array}{l}\text { Severe drought occurred in more than three } \\
\text { regions in } 1918 \text {, such as Bachu, Jiashi, } \\
\text { Yecheng, etc. }\end{array}$ \\
\hline 7 & $1919(27.27 \%)$ & Drought occurred in Yanqi region in 1919. \\
\hline 8 & $1921(16.32 \%)$ & $\begin{array}{l}\text { In Yining, Turpan, Shanshan and other } \\
\text { counties, summer and autumn drought, } \\
\text { summer crops failed to harvest, autumn grain } \\
\text { difficult to replant. }\end{array}$ \\
\hline 9 & $1938(4.10 \%)$ & $\begin{array}{l}\text { In Yili area, flood and drought alternate, and } \\
\text { lack of rain in summer and autumn, field } \\
\text { seedlings dry account for } 9 \text { out of } 10 .\end{array}$ \\
\hline 10 & $1945(14.53 \%)$ & Drought occurred in Miquan region in 1945. \\
\hline 11 & $1680(-27.57 \%)$ & Tongkoko in Sulawesi (1680). \\
\hline 12 & $1696(-26.04 \%)$ & Komaga-Take in Japan (1695). \\
\hline 13 & $1708(-19.07 \%)$ & Fuji, Japan (1707). \\
\hline$\overline{14}$ & $1784(-9.69 \%)$ & Laki in Iceland (1783). \\
\hline 15 & $1800(-14.83 \%)$ & St Helens in the US (1800). \\
\hline 16 & $1812(-19.45 \%)$ & Awu in Indonesia (1812). \\
\hline 17 & $1815(-18.36 \%)$ & Tambora in Indonesia (1815). \\
\hline$\overline{18}$ & $1854(-2.15 \%)$ & Sheveluch, Kamchatka (1854). \\
\hline 19 & $1883(-22.86 \%)$ & Krakatau, west of Java (1883). \\
\hline 20 & $1886(-4.70 \%)$ & Okataina in New Zealand (1886). \\
\hline 21 & $1903(-5.32 \%)$ & Santa Maria, Guatemala (1902). \\
\hline 22 & $1983(-8.59 \%)$ & El Chichon, Mexico (1982). \\
\hline
\end{tabular}


reconstruction values with the North Atlantic Oscillation Index (NAO) indicated that the climate might be affected by the NAO in the study regions: the values included 2.06 (2.07), 3.90 (3.91), 3.96 (3.95), 5.44 (5.43), 5.56 (5.57), 64.10 (63.69), 72.99 (72.99), 102.04 (102.04) and 113.64 (113.64), respectively. The climate is influenced mainly by the westerly circulations in the Tianshan Mountains, showing that the warm wet air in the Atlantic Ocean enters the Xinjiang regions driven by the westerly wind circulations and affects the trees in the Yili Valley and the western Tianshan Mountains. Moreover, the

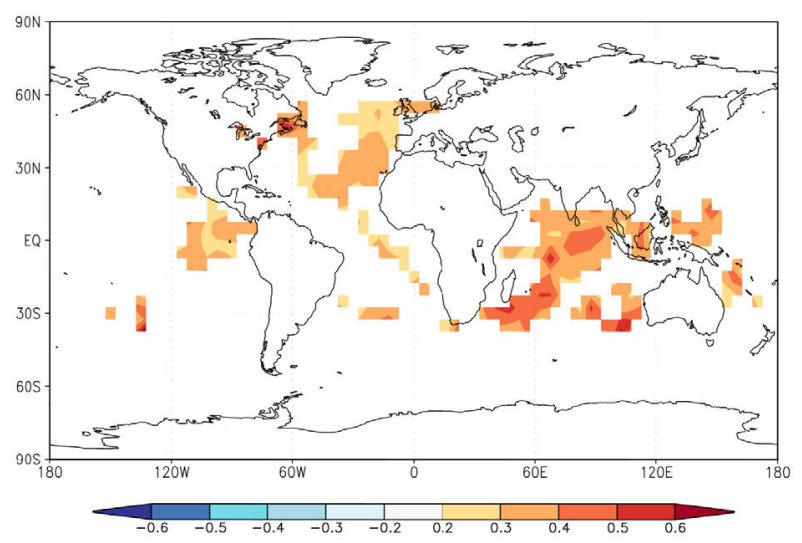

Fig. 11. Field correlation between the reconstructed $T_{\text {mins-- }}$ and SST (1901-2012). temperature changes in the cycle in the range of 5.4-5.9 and 3.9 years might be affected by the El Niño-Southern Oscillation (ENSO), and in the range of approximately 2.1 years, these changes might be related to tropical biennial oscillation (TBO) (Allan et al., 1996).

On the other hand, regarding the spatial correlations between the reconstruction values and the global sea surface temperature (SSTs) in May to September, the reconstruction was strongly correlated with the northern Atlantic, western Pacific and Indian Oceans (Fig. 11). Fig. 12a shows that the reconstruction values were significantly correlated with the North Atlantic Oscillation Index in the summer (SNAO, Folland et al., 2009), with the high-frequency change in March to September $(r=0.221, p<0.05,1930-2012)$ and the low-frequency change occurring with the 5-year moving average $(r=0.366, p<0.01,1930-2012)$. The same conclusion has been found in the reconstruction of precipitation over the last 300 years in the west-central Tianshan Mountains, the reconstruction of drought in the past 364 years in the central and western Tianshan Mountains, and the streamflow reconstruction of the eastern Tianshan Mountains over the past 330 years (Wang et al., 2015; Chen and Yuan, 2016; Zhang et al., 2017). The reconstruction results were correlated with the Western Pacific Oscillation Index

(WPO, https:/crudata.uea.ac.uk/cru/data/wpo/), with the highfrequency change in April to August $(r=0.331, p<0.01$, 1950-2012) and the low-frequency change occurring with the 5-year moving average $(r=0.528, p<0.01$,
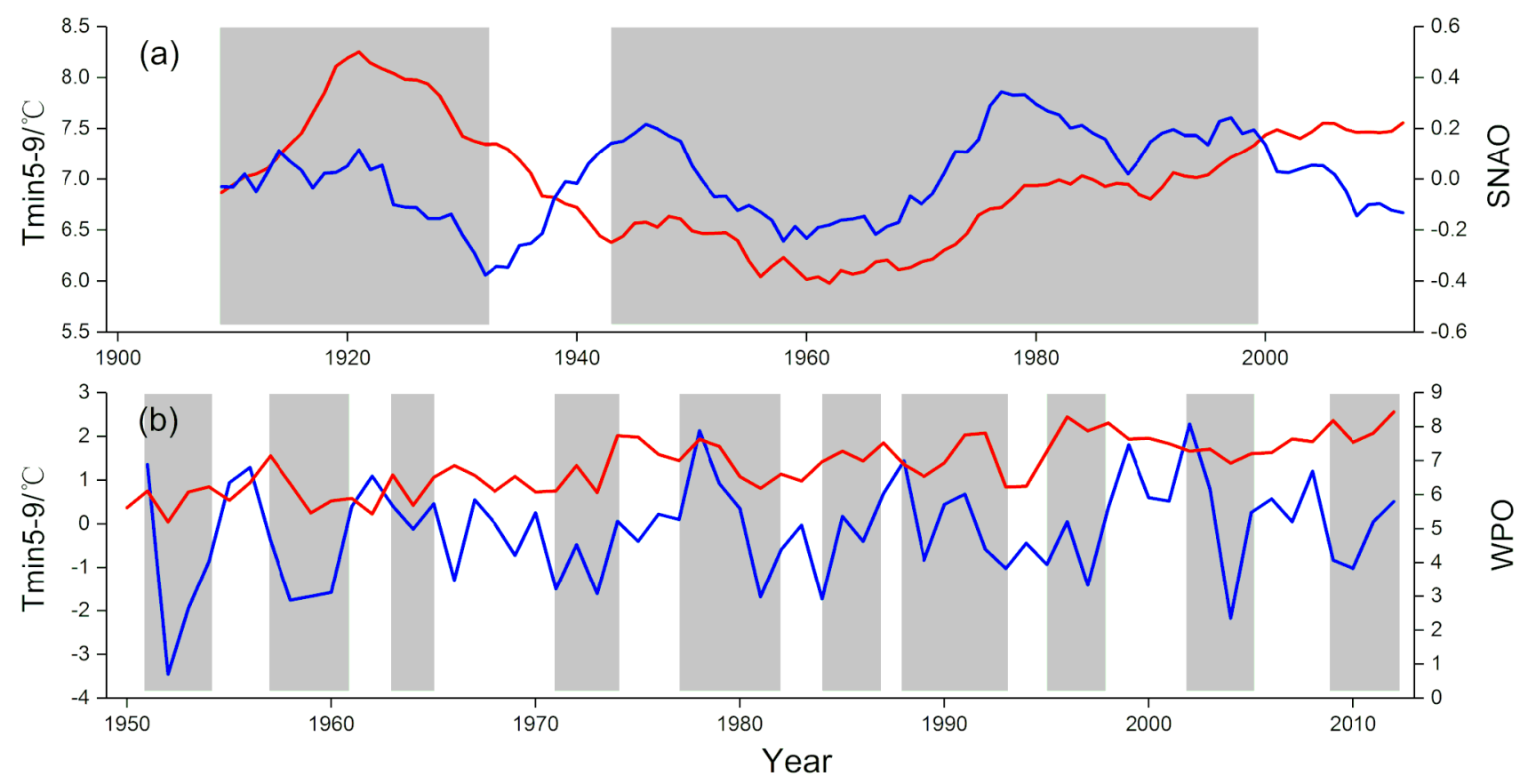

Fig. 12. Comparison of correlations between reconstructed $T_{\text {min5-9 }}$ (red line) and SNAO (a) in March to September (blue line) and WPO (b) in August to September (blue line). The gray area represents the consistency of fluctuations between series. 
1950-2012), which indicates that the change in the sea temperature in the Western Pacific Ocean has an important influence on the temperature of the study area in the summer (Fig. 12b). Similar results have been found in other studies ( $\mathrm{Yu}$ et al., 2013). Based on the above results, large-scale atmospheric-oceanic variability is also a major driving force for surface temperature changes in the study regions.

\section{CONCLUSIONS}

The tree-ring chronology was developed by samples of Schrenk spruce collected from the National Nature Reserve of the Western Tianshan Mountains. The mean minimum temperature in the growing season is the main and stable limiting climate factor. Therefore, the mean minimum temperature series in the growing season during 1680-2012 was reconstructed based on the STD chronology. In the past 333 years, the mean minimum temperature has roughly experienced three relatively cold periods and relatively warm stages (relatively cold periods: $1680-1707,1802-1911$ and 1935-1997; relatively warm periods: 1708-1801, 1912-1934 and 1998-2012). By analyzing similar trends in regional temperature changes in our reconstruction series with drought events, large volcanic eruptions and other reconstruction series around the study regions in Xinjiang and even large-scale regions, we found that the mean minimum temperature of the reconstruction was accurate and reliant. Moreover, the mean minimum temperature was influenced by solar activity (sunspots) and large-scale atmospheric-oceanic fluctuations (NAO, WPO, ENSO, TBO) based on the MTM and spatial correlation analysis.

\section{ACKNOWLEDGMENTS}

This research was supported by the National Natural Science Foundation of China (Projects No. 41630750 and 41861006) and the Scientific Research Program of Higher Education Institutions of Gansu Province (2018C-02). We also thank the anonymous referees for helpful comments on the manuscript.

\section{REFERENCES}

Allan R, Lindesay J and Parker D, 1996. El Nino: Southern Oscillation and Climatic Variability. CSIRO Publishing, Collinwood.

Beguería S and Vicente-Serrano SM, 2013. SPEI: calculation of the standardised precipitation-evapotranspiration index. Retrieved from http://cran.r-project.org/package=SPEI.

Biondi F and Waikul K, 2004. DENDROCLIM2002: AC++ program for statistical calibration of climate signals in tree-ring chronologies. Computers \& Geosciences 30: 303-311, DOI 10.1016/j.cageo.2003.11.004.

Briffa KR, Schweingruber FH, Jones PD, Osborn TJ, Shiyatov SG and Vaganov EA, 1998. Reduced sensitivity of recent tree-growth to temperature at high northern latitudes. Nature 391: 678-682, DOI $10.1038 / 35596$.

Büntgen U, Tegel W, Nicolussi K, Mccormick M, Frank D, Trouet V, Kaplan J, Herzig F, Heussner KU, Wanner H, Luterbacher J and
Esper J, 2011. 2500 Years of European Climate Variability and Human Susceptibility. Science 331: 578-582, DOI 10.1126/science.1197175.

Chen F, Shang HM and Yuan YJ, 2016. Dry/wet variations in the eastern Tien Shan (China) since AD 1725 based on Schrenk spruce (PiceaschrenkianaFisch. etMey) tree rings. Dendrochronologia 40: 110-116, DOI 10.1016/j.dendro.2016.07.003.

Chen F and Yuan YJ, 2016b. Erratum to: streamflow reconstruction for the Guxiang river, eastern Tienshan (China): linkages to the surrounding rivers of central Asia. Environmental Earth Sciences 75: 1049-1057, DOI 10.1007/s12665-016-5849-1.

Chen F, Yuan YJ, Chen FH, Wei WS, Yu SL, Chen XJ, Fan ZA, Zhang RB, Zhang TW, Shang HM and Qin L, 2013. A 426-year drought history for western Tianshan, Central Asia, inferred from tree rings and linkages to the North Atlantic and Indo-West Pacific Oceans. Holocene 23: 1095-1104, DOI 10.1177/0959683613483614.

Chen F, Yuan YJ, Wei WS, Wang L, Yu SL, Zhang RB, Fan ZA, Shang HM, Zhang TW and Li Y, 2012a. Tree ring density-based summer temperature reconstruction for Zajsan Lake area, East Kazakhstan. International Journal of Climatology 32: 1089-1097, DOI 10.1002/joc.2327.

Chen F, Yuan YJ and Yu SL, 2017. Tree-ring indicators of rainfall and streamflow for the ili-balkhash basin, central asia since ce 1560 . Palaeogeography Palaeoclimatology Palaeoecology 482: 48-56, DOI 10.1016/j.palaeo.2017.05.029.

Chen ZJ, Zhang XL, Cui MX and He XY, 2012b. Tree-ring based precipitation reconstruction for the forest-steppe ecotone in northern Inner Mongolia, China and its linkages to the Pacific Ocean variability. Global Planetary Change 86-87: 45-56, DOI 10.1016/j.gloplacha.2012.01.009.

Chen J, Wang LL, Zhu HF and Wu P, 2009. Reconstructing mean maximum temperature of growing season from the maximum density of the Schrenk Spruce in Yili, Xinjiang, China. Chinese Science Bulletin 54: 2300-2308, DOI 10.1007/s11434-009-0051-4.

Cheng H, Zhang PZ, Spötl C, Edwards RL, Cai YJ, Zhang DZ, Sang WC, Tan M and An ZS, 2012. The climatic cyclicity in semiaridarid central Asia over the past 500,000 years. Geophysical Research Letters 39: 1705-1709, DOI 10.1029/2011GL050202.

Cook ER, Anchukaitis KJ, Buckley BM, D'Arrigo RD, Jacoby GC and Wright WE, 2010. Asian Monsoon Failure and Megadrought during the Last Millennium. Science 328: 486-489, DOI 10.1126/science.1185188.

Cook ER and Kairiukstis LA, 1990. Methods of dendrochronology: applications in the environmental sciences. Kluwer Academic, Dordrecht.

Cook ER, Krusic PJ and Melvin T, 2013. Program RCSigFree: version 43ptr05. Lamont-Doherty Earth Obs. Columbia University, Palisades, NY.

D'Arrigo R, Wilson R, Liepert B and Cherubini P, 2008. On the 'Divergence Problem' in Northern Forests: A review of the tree-ring evidence and possible causes. Global Planetary Change 60: 289-305, DOI 10.1016/j.gloplacha.2007.03.004.

Fan MJ, Yuan YJ, Wei WS and Yu SL, 2008. Interpolation and Analysis of Mean Summer Maximum Temperature in Yili Prefecture in the West Tianshan Mountains, China. Arid Zone Research 25: 7581 (in Chinese, with English Abstract).

Fang KY, Davi N, Gou XH, Chen FH, Cook ER, Li JB and D'Arrigo R, 2010. Spatial drought reconstructions for central High Asia based on tree rings. Climate Dynamics 35: 941-951, DOI 10.1007/s00382-009-0739-9.

Folland CK, Knight J, Linderholm HW, Fereday D, Ineson S and Hurrell JW, 2009. The Summer North Atlantic Oscillation: Past, Present, and Future. Journal of Climate 22: 1082-1103, DOI 10.1175/2008JCLI2459.1.

Franceschini T, Bontemps JD, Leban JM, 2012. Transient historical decrease in earlywood and latewood density and unstable sensitivity to summer temperature for Norway Spruce in northeastern France. Revue Canadienne De Recherche Forestière 42: 219-226, DOI 10.1139/x11-182.

Fritts H, 1976. Tree rings and climate. Academic, London. 
Holmes RL, 1983. Computer-Assisted Quality Control in Tree-Ring Dating and Measurement. Tree-Ring Bulletin 43: 69-75.

IPCC, 2013. Climate Change 2013: The Physical Science Basis: Contribution of Working Group I to the Fifth Assessment Report of the Intergovernmental Panel on Climate Change. Cambridge University Press, Cambridge.

Jiang P, Liu HY, Wu XC and Wang HY, 2017. Tree-ring-based SPEI reconstruction in central Tianshan Mountains of China since A.D. 1820 and links to westerly circulation. International Journal of Climatology 37: 2863-2872, DOI 10.1002/joc.4884.

Jiao L, Jiang Y, Wang MC, Kang XY, Zhang WT, Zhang LN and Zhao SD, 2016. Responses to climate change in radial growth of Picea Schrenkiana along elevations of the eastern Tianshan Mountains, northwest China. Dendrochronologia 40: 117-127, DOI 10.1016/j.dendro.2016.09.002.

Jiao L, Jiang Y, Wang MC, Zhang WT and Zhang YP, 2017. Age-effect Radial Growth Responses of Picea Schrenkiana to Climate Change in the Eastern Tianshan Mountains, Northwest China. Forests 8: 294-310, DOI 10.3390/f8090294.

Jiao L, Jiang Y, Zhang WT, Wang MC, Zhang LN and Zhao SD, 2015. Divergent responses to climate factors in the radial growth of Larix sibirica in the eastern Tianshan Mountains, northwest China. Trees 29: 1673-1686, DOI 10.1007/s00468-015-1248-6.

Jones PD and Harris IC, 2008. Climatic Research Unit (CRU) time series datasets of variations in climate with variations in other phenomena, NCAS British Atmospheric Data Centre.

Li JB, Gou XH, Cook ER and Chen FH, 2006. Tree-ring based drought reconstruction for the central Tien Shan area in northwest China. Geophysical Research Letters 33: 408-12, DOI 10.1029/2006GL025803.

Linderholm HW, Björklund J, Seftigen K, Gunnarson BE and Fuentes M, 2015. Fennoscandia revisited: a spatially improved tree-ring reconstruction of summer temperatures for the last 900 years. Climate Dynamics 45: 933-947, DOI 10.1007/s00382-014-2328-9.

Liu WH, Gou XH, Li JB, Huo YX and Fang KY, 2015. A method to separate temperature and precipitation signals encoded in tree-ring widths for the western Tien shan Mountains, northwest China. Global Planetary Change 133: 141-148, DOI 10.1016/j.gloplacha.2015.08.002.

Liu N, Liu Y, Zhou Q and Bao G, 2013. Droughts and broad-scale climate variability reflected by temperature-sensitive tree growth in the Qinling Mountains, central China. International Journal Biometeorology 57: 169-177, DOI 10.1007/s00484-012-0544-8.

Liu WH, Gou XH, Yang MX, Zhang Y, Fang KY, Yang T and Jin LY, 2009. Drought reconstruction in the Qilian Mountains over the last two centuries and its implications for large-scale moisture patterns. Advances in Atmospheric Sciences 26 (4): 621-629, DOI 10.1007/s00376-009-9028-0.

Mann ME and Lees JM, 1996. Robust estimation of background noise and signal detection in climatic time series. Climatic Change 33: 409-445, DOI 10.1007/BF00142586.

Marcott SA, Shakun JD, Clark PU and Mix AC, 2013. A Reconstruction of Regional and Global Temperature for the Past 11,300 years. Science 339: 1198-1201, DOI 10.1126/science.1228026.

Matskovsky V, Dolgova E, Lomakin N and Matveev S, 2017. Dendroclimatology and historical climatology of Voronezh region, European Russia, since 1790s. International Journal of Climatology 37(7): 3057-3066, DOI 10.1002/joc.4896.

Melvin TM and Briffa KR, 2008. A "signal-free" approach to dendroclimatic standardisation. Dendrochronologia 26: 71-86, DOI 10.1016/j.dendro.2007.12.001.

Palombo C, Battipaglia G, Cherubini P, Chirici G, Garfi V, Lasserre B, Lombardi M, Marchetti M and Tognetti R, 2014. Warming-related growth responses at the southern limit distribution of mountain pine (PinusMugoTurra subsp. mugo). Journal of Vegetation Science 25: 71-583, DOI 10.1111/jvs.12101.

Pederson N, Hessl AE, Baatarbileg N, Anchukaitis KJ and Di CN, 2014. Pluvials, droughts, the Mongol empire, and modern Mongolia. Proc Natl Acad Sci USA 111: 4375-4379, DOI 10.1073/pnas.1318677111.
Peng JF, Gou XH, Chen FH and Li JB, 2005. Climatic records of treering width in Picea schrenkiana Fisch and Larix sibirica Ledb. Ecology and Environment 14: 460-465 (in Chinese).

Peng JJ, Sun Y, Chen M, He XY, Davi NK, Zhang XL,Li T, Zhu CY, Cai $\mathrm{C}$ and Chen ZJ, 2013. Tree-ring based precipitation variability since AD 1828 in northwestern Liaoning, China. Quaternary International 283(427): 63-71, DOI 10.1016/j.quaint.2012.07.007.

Ponocná T, Spyt B, Kaczka R, Büntgen U and Treml V, 2016. Growth trends and climate responses of Norway spruce along elevational gradients in East-Central Europe. Trees 30: 1-14, DOI 10.1007/s00468-016-1396-3.

Popa I and Kern Z, 2009. Long-term summer temperature reconstruction inferred from tree-ring records from the Eastern Carpathians. Climate Dynamics 32(7-8): 1107-1117, DOI 10.1007/s00382008-0439-x.

R Core Team, 2014. R: a language and environment for statistical computing. Retrieved from http://www.r-project.org/.

Rydval M, Loader NJ, Gunnarson BE, Druckenbrod DL, Linderholm HW, Moreton SG, Wood CV and Wilson R, 2017. Reconstructing 800 years of summer temperatures in Scotland from tree rings. Climate Dynamics 49: 1-24, DOI 10.1007/s00382-016-3478-8.

Schweingruber FH, 1996. Tree rings and environment: Dendroecology. Vienna Paul Haupt, Bern; Stuttgart, pp. 1-609.

Shang HM, Wei WS, Yuan YJ, Yu SL, Chen X, Zhang TW and Liu XH, 2010. The 150-year Precipitation Change Recorded by Tree Ring in the Central Tianshan Mountains. Arid Zone Research 27: 443-449 (in Chinese, with English Abstract).

Shang HM, Wei WS, Yuan YJ, Yu SL and Zhang TW, 2011. Variations of temperature during last 350 years at XinYuan recorded by treering. Journal of Arid land Resources and Environment 25: 187190, DOI 10.1016/j.quascirev.2010.05.005.

Shao XM, Xu Y, Yin ZY, Liang EY, Zhu HF and Wang SZ, 2010. Climatic implications of a 3585-year tree-ring width chronology from the northeastern Qinghai-Tibetan Plateau. Quaternary Science Reviews 29: 2111-2122, DOI 10.1016/j.quascirev.2010.05.005.

Shao XM, Huang L, Liu HB, Liang EY, Fang XQ and Wang LL, 2005. Reconstruction of precipitation variation from tree rings in recent 1000 years in Delingha, Qinghai. Science in China 48: 939-949, DOI 10.1360/03yd0146.

Shen CC, Wang LL and Li MY, 2016. The altitudinal variability and temporal instability of the climate-tree-ring growth relationships for Changbai larch (Larix Olgensis Henry) in the Changbai Mountains area, Jilin, Northeastern China. Trees 30: 901-912, DOI 10.1007/s00468-015-1330-0.

Shi YF, Shen YP, Kang ES, Li DL, Ding YJ, Zhang GW and Hu RJ, 2007. Recent and Future Climate Change in Northwest China. Climatic Change 80: 379-393, DOI 10.1007/s10584-006-9121-7.

Wang WZ, Liu XH, Xu GB, Zeng XM, Wu GJ, Zhang XW and Qin $\mathrm{DH}, 2016$. Temperature signal instability of tree-ring $\delta^{13} \mathrm{c}$ chronology in the northeastern Qinghai-Tibetan Plateau. Global Planetary Change 139: 165-172, DOI 10.1016/j.gloplacha.2016.02.006.

Wang T, Ren GY, Chen F and Yuan YJ, 2015. An analysis of precipitation variations in the west-central Tianshan Mountains over the last 300 years. Quaternary International 358: 48-57, DOI 10.1016/j.quaint.2014.10.051.

Wen KG, Shi YG and Ren YY, 2006. The Documents of Chinese Meteorological Disaster: Volume of Xinjiang. Meteorological Publishers, Beijing (in Chinese, with English Abstract).

White PB, Soulé P and Gevel SVD, 2014. Impacts of human disturbance on the temporal stability of climate-growth relationships in a red spruce forest, southern Appalachian Mountains, USA. Dendrochronologia 32: 71-77, DOI 10.1016/j.dendro.2013.10.001.

Wigley TML, Briffa KR and Jones PD, 1984. On the Average Value of Correlated Time Series, with Applications in Dendroclimatology and Hydrometeorology. Journal of Climate Applied Meteorology 23: 201-213, $\quad$ DOI $10.1175 / 1520-$ 0450(1984)023<0201:OTAVOC $>2.0 . C O ; 2$.

Wilson R and Elling W, 2004. Temporal instability in treegrowth/climate response in the Lower Bavarian Forest region: im- 
plications for dendroclimatic reconstruction. Trees 18: 19-28, DOI 10.1007/s00468-003-0273-z.

Wu GJ, Xu GB, Chen T, Liu XH, Zhang YF, An WL, Wang WZ, Fang ZA and Yu SL, 2013. Age-dependent tree-ring growth responses of Schrenk Spruce (Picea Schrenkiana) to climate-A case study in the Tianshan Mountain, China. Dendrochronologia 31: 318-326, DOI 10.1016/j.dendro.2013.01.001.

Xu GB, Liu XH, Qin DH, Chen T, Wang WZ, Wu GJ, Sun WZ, An WL and Zeng XM, 2015a. Tree-ring $\delta 180$ evidence for the drought history of eastern Tianshan Mountains, northwest China since 1700 AD. International Journal of Climatology 34: 3336-3347, DOI 10.1002/joc. 3911.

Xu GB, Liu XH, Wu GJ, Chen T, Wang WZ, Zhang Q, Zhang YF, Zeng XM, Qin DH, Sun WZ and Zhang XW, 2015b. Tree ring $\delta^{18} \mathrm{O}$ 's indication of a shift to a wetter climate since the $1880 \mathrm{~s}$ in the western Tianshan Mountains of northwestern China. Journal of Geophysical Research Atmospheres 120: 6409-6425, DOI 10.1002/2014JD023027.

Yang YH, Chen YN, Wang MZ and Sun HL, 2016. Reconstruction and analysis of the past five centuries of streamflow on northern slopes on Tianshan Mountains in Northern Xinjiang, China. Theoretical and Applied Climatology 129: 1-8, DOI 10.1007/s00704-0161772-3.

Yang B, Qin C, Bräuning A, Burchardt I and Liu J, 2011. Rainfall history for the Hexi corridor in the arid northwest China during the past 620 years derived from tree rings. International Journal of Climatology 31: 166-1176, DOI 10.1002/joc.2143.

Yu SL, Yuan YJ, Qin L, Zhang TW, Chen F, Shang HM, Zhang RB and Cai XT, 2012. Reconstruction and analysis of the minimum temperature in summer for the Shawan in the Tianshan Mountains. Journal Earth Environment 3: 868-873 (in Chinese, with English Abstract).

Yu SL, Yuan YJ, Wei WS, Chen F, Zhang TW, Shang HM, Zhang RB and Li Q, 2013. A 352-year record of summer temperature reconstruction in the western Tianshan Mountains, China, as deduced from tree-ring density. Quaternary Research 80: 158-166, DOI 10.1016/j.yqres.2013.05.005.

Yu J, Zhou G and Liu QJ, 2018. Tree-ring based summer temperature regime reconstruction in XiaoXing Anling Mountains, northeastern china since 1772 CE. Palaeogeography Palaeoclimatology Palaeoecology 495: 13-23, DOI 10.1016/j.palaeo.2017.11.046.

Yuan YJ, Li JF and Zhang JB, 2001. 348-year precipitation reconstruction from tree-rings for the north slope of the middle Tianshan Mountains. Journal of Meteorological Research 15: 95-104 (in Chinese, with English Abstract).

Yuan YJ, Shao XM, Wei WS, Yu SL, Yuan G and Trouet V, 2007. The Potential to Reconstruct Manasi River Streamflow in the northern
Tien Shan Mountains (NW China). Tree-Ring Research 63: 81-93, DOI 10.3959/1536-1098-63.2.81.

Zhang RB, Qin L, Yuan YJ, Gou XH, Zou C, Yang Q, Shang HM and Fan ZA, 2016. Radial growth response of Populus xjrtyschensis to environmental factors and a century-long reconstruction of summer streamflow for the Tuoshigan River, northwestern China. Ecological Indicators 71: 191-197, 10.1016/j.ecolind.2016.06.035.

Zhang RB, Yuan YJ, Yu SL, Chen F and Zhang TW, 2017. Past changes of spring drought in the inner Tianshan Mountains, China, as recorded by tree rings. Boreas 46: 688-696, DOI 10.1111/bor. 12238

Zhang TW, Yuan YJ, Liu Y, Wei WS, Zhang RB, Chen F, Yu SL, Shang HM and Li Q, 2013a. A tree-ring based temperature reconstruction for the Kaiduhe River watershed, northwestern China, since AD. 1680: Linkages to the North Atlantic Oscillation. Quaternary International 311: 71-80, DOI 10.1016/j.quaint.2013.07.026.

Zhang TW, Yuan YJ, Liu Y, Wei WS, Yu SL, Chen F, Fan ZA, Shang $\mathrm{HM}$, Zhang RB and Li Q, 2013b. A tree-ring based precipitation reconstruction for the Baluntai region on the southern slope of the central Tien Shan Mountains, China, since AD. 1464. Quaternary International 283: 55-62, DOI 10.1016/j.quaint.2012.03.037.

Zhang TW, Zhang RB, Yuan YJ, Gao YQ, Wei WS, Diushen M, He Q, Shang HM and Wang J, 2015. Reconstructed precipitation on a centennial timescale from tree rings in the western Tien Shan Mountains, Central Asia. Quaternary International 358: 58-67, DOI 10.1016/j.quaint.2014.10.054.

Zhang Y, Tian QH, Gou XH and Chen FH, 2011. Annual precipitation reconstruction since $\mathrm{AD} 775$ based on tree rings from the Qilian Mountains, northwestern China. International Journal of Climatology 31(3): DOI 10.1002/joc.2085.

Zhang YX, Wilmking M and Gou XH, 2009. Changing relationships between tree growth and climate in Northwest China. Plant Ecology 201: 39-50, DOI 10.1007/978-90-481-2795-5_4.

Zhang YX and Wilmking M, 2010. Divergent growth responses and increasing temperature limitation of Qinghai spruce growth along an elevation gradient at the northeast Tibet Plateau. Forest Ecology \& Management 260: 1076-1082, DOI 10.1016/j.foreco.2010.06.034.

Zhang YP, Xu JL, Su W, Zhao XP and Xu XL, 2018. Spring precipitation effects on formation of first row of earlywood vessels in Quercus variabilis at Qinling Mountain (China). Trees 29: 16731686, DOI 10.1007/s00468-018-1792-y.

Zhu HF, Shao XM, Yin ZY and Huang L, 2011. Early summer temperature reconstruction in the eastern Tibetan plateau since ad 1440 using tree-ring width of Sabina tibetica. Theoretical \& Applied Climatology 106(1-2):45-53, DOI 10.1007/s00704-011-0419-7. 